\title{
(")
}

ISSN 2238-4502

\section{SOBRE O ENSINO DOS TEXTOS LITERÁRIOS NOS MANUAIS DIDÁTICOS DE PORTUGUÊS NA CHINA}

\author{
Zhihua $\mathrm{Hu}$ \\ Zhejiang International Studies University \\ (China) \\ (zhihua.hu@ua.pt,_ramonhu@outlook.com)
}

\author{
Maria Teresa Roberto \\ Universidade de Aveiro (Portugal) \\ mariateresaroberto@ua.pt
}

\section{Resumo}

Neste trabalho, analisamos a relação entre a língua e a literatura em duas séries de manuais didáticos de português na China, com foco no ensino dos textos literários, nesses manuais. Foram escolhidas duas séries de manuais de português: "Português para Ensino Universitário" e "Curso de Português para Chineses". Na análise, evidenciou-se que, para a primeira série, existem só trava-línguas e poemas que podem ser considerados como textos literários; e para a segunda série, há uma unidade destinada exclusivamente a textos literários. Porém, em comparação com os manuais mais maduros de outras línguas estrangeiras, como a série "Español Moderno", o ensino dos textos literários nas duas séries de manuais de português tem ainda vários aspetos a serem melhorados, tais como a quantidade insuficiente de textos literários, a falta de exercícios destinados à compreensão dos textos literários e das informações biográficas dos escritores, entre outros.

Palavras-chave: Ensino de literatura. Manuais de português. Instituições chinesas. Licenciatura de português.

DOI: https://doi.org/10.32988/rep.v10n1.1156

Dossiê "Possibilidades de trabalho com a Língua Portuguesa"

\begin{tabular}{|l|l|l|l} 
Revista (Entre Parênteses) & Alfenas, MG & v. 10 & n. 1
\end{tabular}




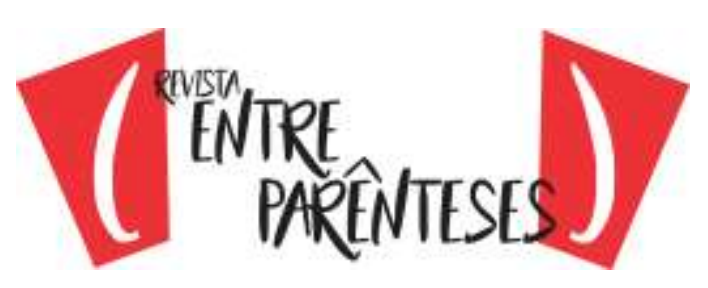

ISSN 2238-4502
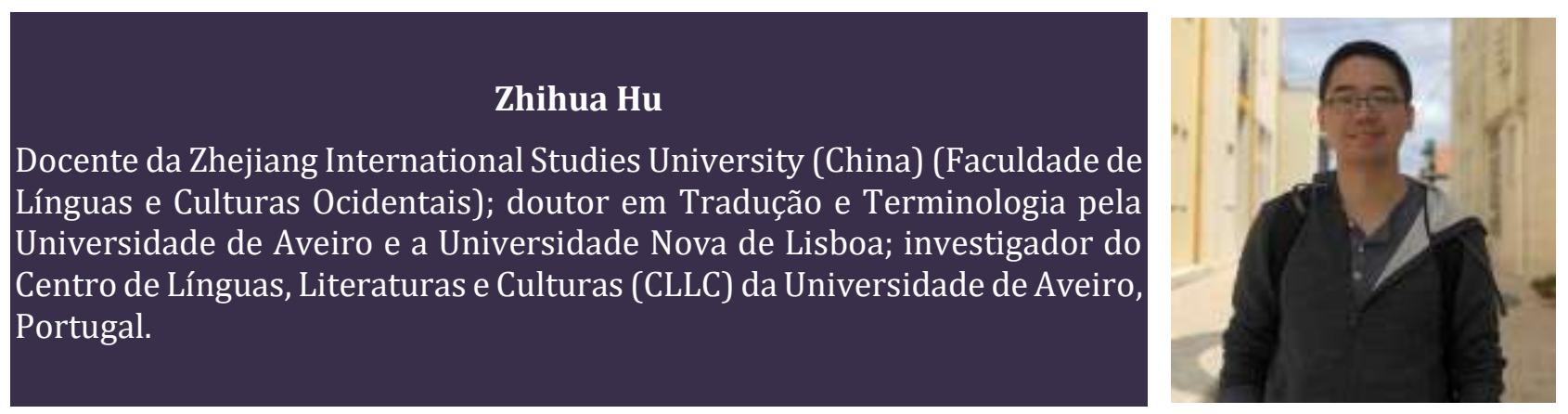

https://orcid.org/0000-0002-2235-8877

DOI: https://doi.org/10.32988/rep.v10n1.1156

Dossiê "Possibilidades de trabalho com a Língua Portuguesa"

Revista (Entre Parênteses) Alfenas, MG

v. 10

n. 1

$1-24$

$\mathrm{e} 021010$

Universidade Federal de Alfenas

Departamento de Letras - Instituto de Ciências Humanas e Letras

Rua Gabriel Monteiro da Silva, 700 - Alfenas/MG - CEP 317131-001 - Brasil

https://publicacoes.unifal-mg.edu.br/revistas/index.php/entreparenteses/about 


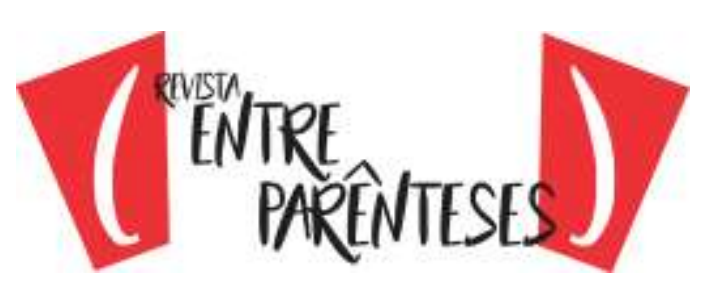

ISSN 2238-4502

\section{Maria Teresa Roberto}

Docente no Departamento de Línguas e Culturas, da Universidade de Aveiro. Dirige o Programa Doutoral de Tradução e Terminologia; uma parceria da Universidade de Aveiro com a Universidade Nova de Lisboa, Portugal. Atualmente, é coordenadora da Linha de Investigação em Tradução e Terminologia, do Centro de Línguas, Literaturas e Culturas.
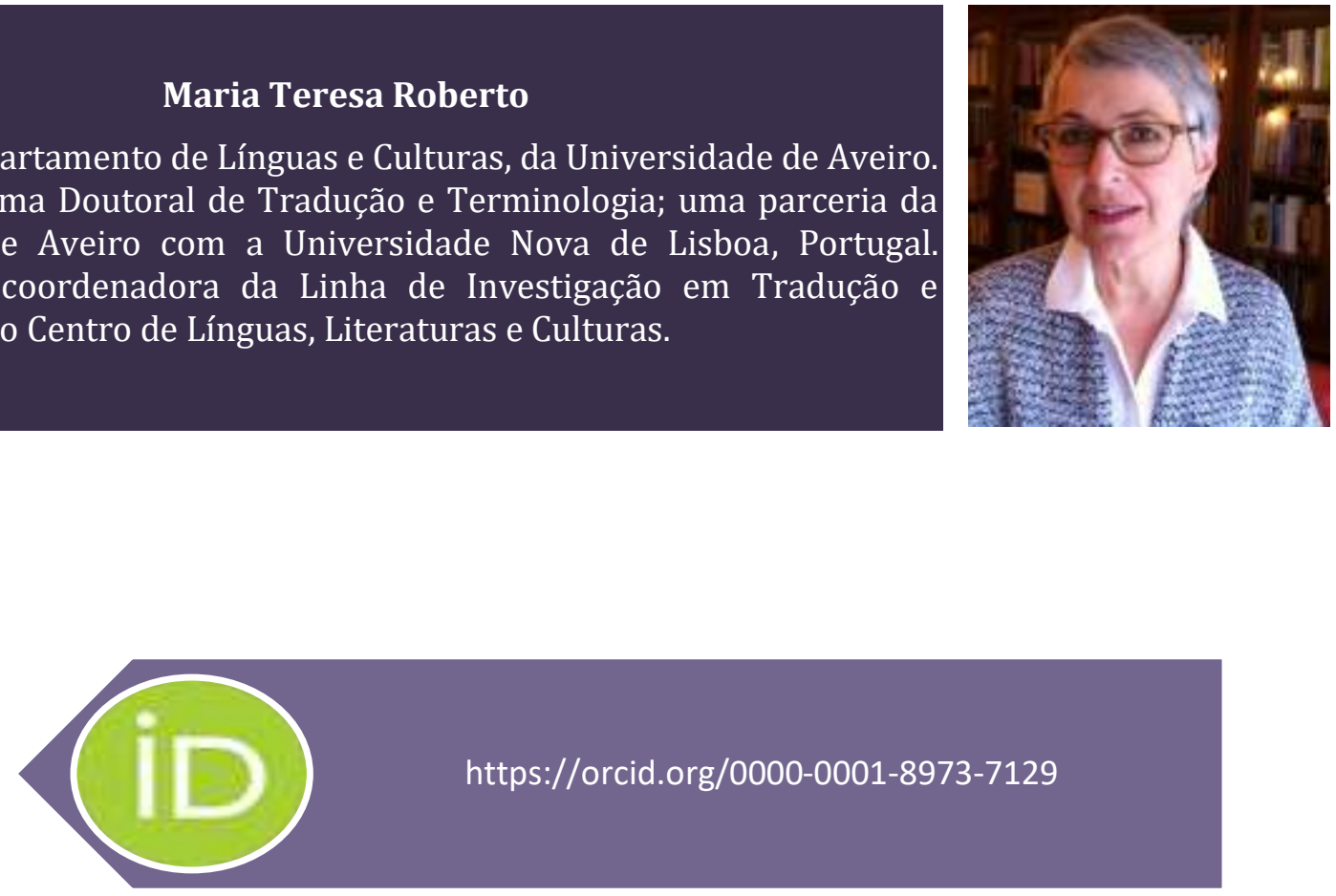

DOI: https://doi.org/10.32988/rep.v10n1.1156

Dossiê "Possibilidades de trabalho com a Língua Portuguesa"

v. 10

n. 1

$1-24$

$\mathrm{e} 021010$




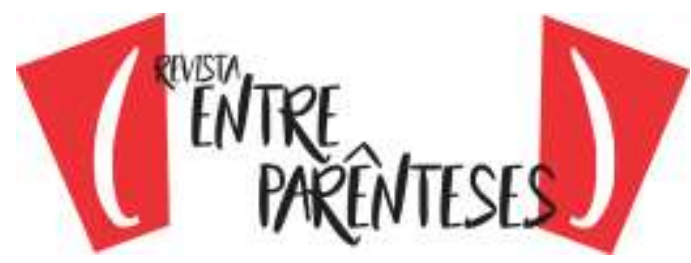

ISSN 2238-4502

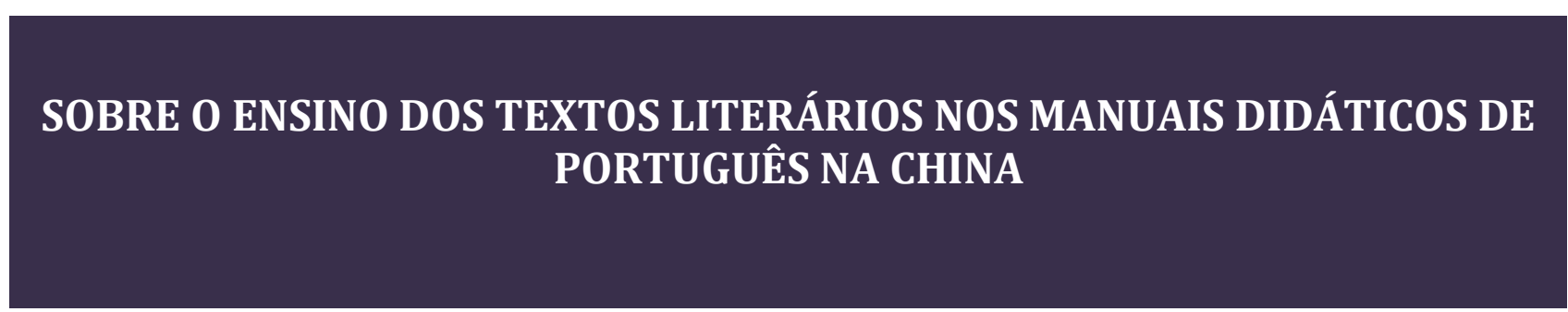

Zhihua $\mathrm{Hu}^{1}$

Zhejiang International Studies University (China)

(zhihua.hu@ua.pt,_ramonhu@outlook.com)
Maria Teresa Roberto ${ }^{2}$

Universidade de Aveiro (Portugal)

mariateresaroberto@ua.pt

\section{Introdução}

De acordo com Wang (2001), o ensino de língua portuguesa na China continental, como um curso de licenciatura, remonta aos anos 60 do século passado. No decorrer desses mais de cinquenta anos, o ensino da língua de Camões tem enfrentado desafios de vária índole, entre os quais se destacam os desafios apresentados por manuais didáticos adotados nas aulas da licenciatura de português. Falando dos apoios didáticos de aprendizagem de línguas estrangeiras, existem tipos muito variados, tais como: os manuais, as gramáticas, os dicionários, entre outros. Para a nossa análise, iremos restringir-nos aos manuais de português usados por instituições chinesas. Concretamente, estamos muito interessados no ensino dos textos literários nesses manuais de português. Pelo limite do espaço do artigo, a nossa abordagem delimita-se ao contexto do continente chinês.

Na realidade, o começo do ensino de língua portuguesa pelas instituições chinesas não foi um caminho suave (a partir da década de 1960), uma vez que, naquela altura, existiam, no continente chinês, muito poucos manuais desta língua para o uso dos docentes e alunos. Conforme Wang (2001), a primeira licenciatura de português no continente chinês data do ano de 1960, com duração de 4 anos e que tinha 18 alunos, no então Instituto de Radiodifusão de

\footnotetext{
1 Docente da Zhejiang International Studies University (China) (Faculdade de Línguas e Culturas Ocidentais); doutor em Tradução e Terminologia pela Universidade de Aveiro e a Universidade Nova de Lisboa; investigador do Centro de Línguas, Literaturas e Culturas (CLLC) da Universidade de Aveiro, Portugal. E-mail: zhihua.hu@ua.pt; ramonhu@outlook.com

2 Docente no Departamento de Línguas e Culturas, da Universidade de Aveiro. Dirige o Programa Doutoral de Tradução e Terminologia; uma parceria da Universidade de Aveiro com a Universidade Nova de Lisboa, Portugal. Atualmente, é coordenadora da Linha de Investigação em Tradução e Terminologia, do Centro de Línguas, Literaturas e Culturas. E-mail: mariateresaroberto@ua.pt
}

DOI: https://doi.org/10.32988/rep.v10n1.1156

Dossiê "Possibilidades de trabalho com a Língua Portuguesa"

\begin{tabular}{|l|l|l|l|l|l|l|} 
Revista (Entre Parênteses) & Alfenas, MG & v. 10 & n. 1 & $1-24$ & e021010 & 2021 \\
\hline
\end{tabular}




\section{("NonTre}

ISSN 2238-4502

Beijing (hoje a Universidade de Comunicações da China); e em dezembro do mesmo ano, começou a primeira turma de português oferecida pelo então Instituto de Línguas Estrangeiras de Beijing (hoje a Universidade de Estudos Estrangeiros de Beijing). No entanto, devido ao impacto da Revolução Cultural (1966 - 1976), houve um intervalo em que as duas universidades referidas acima deixaram de admitir novos alunos: o Instituto de Línguas Estrangeiras de Beijing reabriu a licenciatura em 1973 e o Instituto de Radiodifusão de Beijing voltou a admitir alunos de português só a partir de 2000 (Wang, 2001). Na primavera de 1978, teve início também a primeira licenciatura de português no Instituto de Línguas Estrangeiras de Xangai (hoje a Universidade de Estudos Internacionais de Xangai) (Wang, 2001).

O que se descreve acima pode, basicamente, retratar a situação do início do ensino de português como licenciatura na parte continental chinesa; existe uma extensão temporal relativamente longa em que só duas universidades chinesas possuíam licenciatura de português, a saber, a Universidade de Estudos Estrangeiros de Beijing (desde 1961 até o presente) e a Universidade de Estudos Internacionais de Xangai (desde 1978 até o presente). Estas duas universidades, pela sua história relativamente mais profunda no ensino da língua portuguesa, têm exercido uma influência sobre as universidades que abririam a licenciatura de português posteriormente. Um exemplo bem evidente dessa influência é o manual didático usado no ensino, uma vez que foram os graduados das duas universidades que criaram a licenciatura de português na maioria das universidades chinesas e os manuais didáticos usados por eles na sua licenciatura continuam, muitas vezes, a ser usados também pelos alunos posteriores.

De acordo com a nossa pesquisa, antes de começar a preparação dos seus próprios manuais $^{3}$, as duas universidades mencionadas acima utilizavam os manuais importados de Portugal e do Brasil, tais como a série "Português Sem Fronteira" da Editora Lidel (Portugal); a série "Português XXI" da Editora Lidel (Portugal); a série "Aprender Português" da Editora Texto Editores (Portugal); "Falar, ler, escrever português: um curso para estrangeiros" da Editora Pedagógica e Universitária (Brasil). Depois, com o desenvolvimento da formação da língua portuguesa na China e o aumento da quantidade de universidades onde se oferece a licenciatura de português, os docentes das duas universidades, pela sua experiência enriquecida de ensino de português já de muitos anos, começaram a elaborar os seus próprios manuais, que depois de serem testados nos seus alunos, foram publicados para o uso de outras instituições chinesas: a série "Português para Ensino Universitário" pela Universidade de Estudos Estrangeiros de Beijing (2 volumes: 2009, 2010) e a série "Curso de Português para Chineses" pela Universidade de Estudos Internacionais de Xangai (4 volumes: 2012, 2012, $2014,2016)$. As duas séries, depois do lançamento, começam a ser os principais manuais usados pelas instituições chinesas.

\footnotetext{
3 A série "Português para Ensino Universitário" (2 volumes, elaborada por Ye Zhiliang, professor de português da Universidade de Estudos Estrangeiros de Beijing); a série "Curso de Português para Chineses" (4 volumes, elaborada por Xu Yixing \& Zhang Weiqi, professores de português da Universidade de Estudos Internacionais de Xangai).
}

DOI: https://doi.org/10.32988/rep.v10n1.1156

Dossiê "Possibilidades de trabalho com a Língua Portuguesa"

\begin{tabular}{|l|l|l|l|l|l|l|} 
Revista (Entre Parênteses) & Alfenas, MG & v. 10 & n. 1 & $1-24$ & e021010 & 2021 \\
\hline
\end{tabular}


Deve-se indicar que, além desses manuais produzidos pelos docentes das universidades chinesas, foram publicados, nos últimos dez anos, também outros materiais didáticos, que geralmente são manuais estrangeiros que foram localizados em chinês, tais como o volume 1 da série "Português XXI" da Editora Lidel (Portugal) (publicado pela editora chinesa The Commercial Press em 2019) e o manual "Falar, ler, escrever português: um curso para estrangeiros" (Brasil) (publicado pela editora chinesa Foreign Language Teaching and Research Press em 2014). Aliás, a série "Português Global" do Instituto Politécnico de Macau (4 volumes) (elaborada por duas professoras portuguesas na dita instituição) também já foi introduzida para o continente chinês (publicada pela editora chinesa The Commercial Press em 2016, 2016, $2018,2018)$, ampliando a gama de escolha para os docentes e alunos das instituições chinesas. Não obstante, de acordo com a nossa pesquisa em relação ao uso dos manuais pelas principais instituições chinesas, descobrimos que uma maioria absoluta delas usam os manuais elaborados pelos docentes chineses das duas universidades acima referidas, a saber, a série "Português para Ensino Universitário" pela Universidade de Estudos Estrangeiros de Beijing e a série "Curso de Português para Chineses" pela Universidade de Estudos Internacionais de Xangai.

Tendo tudo isso em conta, no presente trabalho, iremos analisar a relação entre a língua e a literatura nestas duas séries de manuais didáticos, concretamente, o nosso foco irá centrar-se no ensino dos textos literários, nesses manuais.

\section{0 ensino dos textos literários nos manuais de português elaborados pelos professores chineses}

\subsection{Na série "Português para Ensino Universitário"}

Em 2009, foi publicado o primeiro manual de português para os alunos universitários no continente chinês (o volume 1 da série de Português para Ensino Universitário, por Ye Zhiliang, professor de português da Universidade de Estudos Estrangeiros de Beijing); no início do ano seguinte, o volume 2 dessa série também foi publicado. Pelos prefácios da dita série de manuais (os dois volumes têm o mesmo prefácio) (YE, 2009; YE, 2010), o primeiro e o segundo manual destinam-se aos alunos universitários de português do primeiro ano (dois semestres, 32 semanas); no entanto, os dois volumes, devido à sua intensidade de conhecimentos linguísticos, têm sido usados, na prática, para os primeiros dois anos da licenciatura (a licenciatura, na China, dura, geralmente, 4 anos).

Para o primeiro volume (14 unidades), as unidades 1-5 constituem a base de aprendizagem da fonética, e as unidades 6-10 são a fase de aprofundamento do estudo da fonética. De acordo com o autor no prefácio (o prefácio não está paginado), estão incluídos trava-línguas para a exercitação da pronunciação dos alunos. Em certo sentido, esses trava-

DOI: https://doi.org/10.32988/rep.v10n1.1156

Dossiê "Possibilidades de trabalho com a Língua Portuguesa"

\begin{tabular}{|l|l|l|l|l|l|l|} 
Revista (Entre Parênteses) & Alfenas, MG & v. 10 & n. 1 & $1-24$ & e021010 & 2021 \\
\hline
\end{tabular}


línguas também podem ser considerados como textos literários elementares (por mais fáceis que sejam) para os alunos chineses, uma vez que refletem a cultura inerente do povo lusófono e conseguem despertar o interesse dos alunos para com a cultura lusófona, além de ajudar os alunos a exercitar e dominar alguns sons não existentes em chinês. Por exemplo, nos exercícios da unidade 6 do volume 1, encontramos os seguintes treinamentos fonéticos:

1. "O tempo pergunta pro tempo

Quanto tempo o tempo tem.

O tempo responde pro tempo

Que o tempo tem tanto tempo

Quanto tempo o tempo tem". (YE, 2009, p. 93)

2. "Olha o sapo dentro do saco

O saco com sapo dentro,

0 sapo batendo papo

E o papo soltando o vento". (YE, 2009, p. 93)

3. "O sabiá não sabia

Que o sábio sabia

Que o sabiá não sabia assobiar". (YE, 2009, p. 93)

4. "O doce perguntou ao doce

Qual é a doce mais doce

Que o doce de batata-doce

0 doce responde ao doce

Que o doce mais doce

Que o doce de batata-doce

É o doce de doce de batata-doce" (YE, 2009, p. 93)

O primeiro trava-línguas é para exercitar a pronúncia do ditongo /ẽj/, o segundo para treinar a pronúncia /p/ e /k/, o terceiro as combinações "iá" e "ia", o quarto ajuda os alunos a exercitar a velocidade e nitidez da fala. Os trava-línguas constituem, a nosso ver, um bom exercício para o treinamento da pronúncia da língua portuguesa, que pode ajudar os alunos a terem uma fala nítida e clara, além de memorizarem novas palavras. Além disso, os trava-línguas também podem ser usados como um jogo divertido pelos professores para despertar o interesse dos alunos na aprendizagem.

Em relação ao volume 2 da série, de acordo com o autor no prefácio, no intuito de despertar mais interesse dos alunos e deixá-los informados sobre conhecimentos culturais variados do povo lusófono, além de se apresentarem conhecimentos históricos e culturais nos textos em cada unidade, adiciona-se um poema dos escritores portugueses ou brasileiros no final de cada unidade. Relativamente a esses poemas, segundo o autor no prefácio, os professores podem oferecer explicações não muito profundas e o mais importante é exigir que

DOI: https://doi.org/10.32988/rep.v10n1.1156

Dossiê "Possibilidades de trabalho com a Língua Portuguesa"

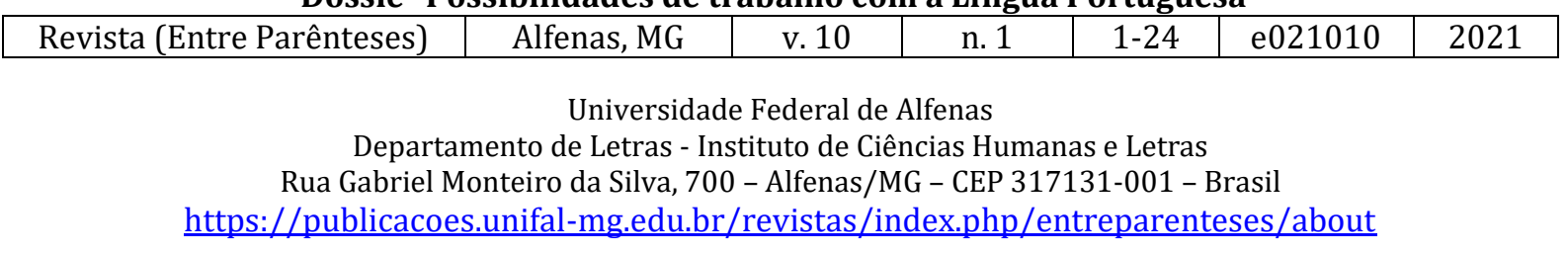




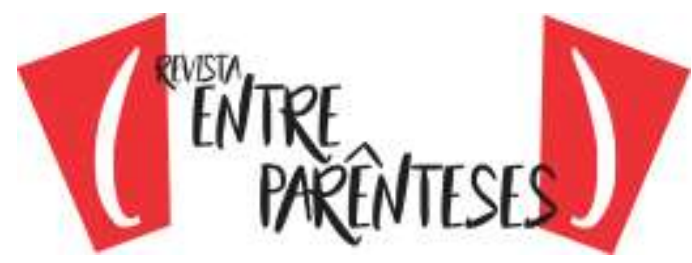

ISSN 2238-4502

de poesia estrangeira publicadas na China (QIU \& WEI, 1986, p. 449; JIANG \& GONG, 1986, p. 70-71; WANG \& LIU, 1996, p.91-92). Na realidade, a tradução de Xiao aparece, pela primeira vez, em 1981, numa breve antologia bilíngue de poemas de Camões, publicada pelo Instituto de Literaturas Estrangeiras da Academia de Ciências Sociais da China com o patrocínio da Fundação Calouste Gulbenkian. Foi a primeira obra de Camões a ser traduzida diretamente do português para o chinês. Aliás, o poema "Alma minha" constante na tabela acima também foi traduzida por Xiao na tradução da antologia de poemas de Camões mencionada acima.

No que diz respeito aos três poemas selecionados de Fernando Pessoa no manual, dois já foram traduzidos e publicados na China: "Mar português" (YANG, 2004, p. 5) e "O infante" (JIN, 1986, p. 68-69); quanto ao poema "Amor", embora haja tradução no website, pelos adeptos internautas chineses ${ }^{4}$, o poema ainda não foi publicado oficialmente. 0 poema "Amor", conforme a nossa pesquisa, pertence a "Poesias Inéditas" de Fernando Pessoa5; como o poema original não tem título, a primeira frase "O amor, quando se revela," foi usado como o título6. Este poema, ao ser escolhido para o manual em questão, foi intitulado de "O amor". Relativamente ao motivo que levou à tradução deste poema pelos adeptos internautas chineses, por um lado, deve-se à popularidade de Fernando Pessoa entre o público leitor chinês: várias das suas obras já foram introduzidas, publicadas e reeditadas na China7; por outro lado, tem muito a ver com a popularização da canção "Presságio" de Salvador Sobral em 20198, uma vez que a tradução feita pelos internautas tem o título de "Presságio", igual ao título da canção de Salvador Sobral, cuja letra se baseia nesse poema de Fernando Pessoa.

Quanto aos poemas de Sophia de Mello Breyner Andresen escolhidos, ambos já foram traduzidos e introduzidos na China. Estes dois poemas foram traduzidos por Yao Jingming e integrados na sua tradução "Poemas de Sophia", que foi publicada na China continental em 1995 pelo Instituto Cultural de Macau e a Editora Montanha das Flores com o patrocínio do Instituto Português do Oriente.

\footnotetext{
${ }^{4}$ https://www.douban.com/note/638284065/, consultado no dia 24 de jan. de 20

${ }^{5} \mathrm{http}: / /$ arquivopessoa.net/textos/1318, consultado no dia 24 de jan. de 20

${ }^{6} \mathrm{http} / / /$ arquivopessoa.net/textos/1318, consultado no dia 24 de jan. de 20

7 "Livro de Desassossego" (1999, 2004, 2012; traduzido por Han Shaogong); “Antologia de Fernando Pessoa" (1988; traduzido por Zhang Weimin); "Mensagem" (1986; traduzido por Jin Guoping); "Alberto Caeiro (Poesia e Prosa)" (2013; traduzido por Min Xuefei); "The Education of The Stoic" (2015; traduzido por Liu Yongjun), "The Book of Disquiet" (2014; traduzido por Liu Yongjun); "Poemas de Fernando Pessoa" (2016; traduzido por Ou Fan); "Selection of Poems of Fernando Pessoa" (2004; traduzido por Yang Zi).

${ }^{8}$ Salvador Sobral é cantor português, nos últimos anos tem gozado de popularidade entre os adeptos músicos chineses; depois de ele vencer o Festival Eurovisão da Canção 2017, no mesmo ano, o Consulado Geral de Portugal em Xangai organizou um concurso para traduzir a sua canção "Amar pelos Dois" do português para o chinês, atraindo a atenção de muitos aprendentes chineses de português.
}

DOI: https://doi.org/10.32988/rep.v10n1.1156

Dossiê "Possibilidades de trabalho com a Língua Portuguesa"

\begin{tabular}{|l|l|l|l|l|l|l} 
Revista (Entre Parênteses) & Alfenas, MG & v. 10 & n. 1 & $1-24$ & e021010 & 2021 \\
\hline
\end{tabular}




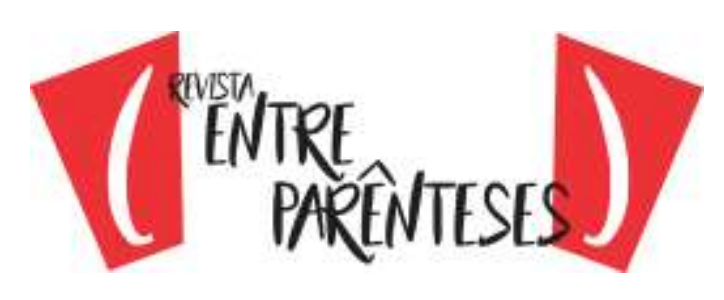

ISSN 2238-4502

Além dos poemas referidos, outros, listados na tabela, ainda não foram traduzidos no continente chinês. Na realidade, só quatro dos escritores listados têm obras traduzidas no continente chinês; além dos anteriormente mencionados (Camões, Fernando Pessoa, Sophia de Mello Breyner), a maior parte das obras de Machado de Assis também já foram traduzidas e introduzidas ao continente chinês (tais como Quincas Borba (1992; 1999); Dom Casmurro (1992; 2001) e Memórias Póstumas de Brás Cubas (1992)). Apesar disso, nenhuma coletânea de poemas de Machado de Assis foi traduzida para o chinês até o presente.

Como se observa na tabela, em comparação com os poetas portugueses, muito poucos poetas brasileiros foram traduzidos para o público leitor chinês. Isso se deve a muitos fatores, por exemplo, a falta do patrocínio (a publicação de algumas obras dos escritores portugueses teve o patrocínio da Fundação Calouste Gulbenkian ou do Instituto Português no Oriente), o desconhecimento pelas editoras e pelos leitores chineses, entre outros.

Este volume da série "Português para Ensino Universitário" foi publicado em 2010. Dez anos depois, em 2020, esta situação ainda não foi mudada. Conforme a nossa pesquisa, nenhuma coletânea dos poetas brasileiros listados foi traduzida para o chinês. Não obstante, isso também pode ser considerado como uma oportunidade, uma vez que os professores podem orientar os alunos a traduzirem esses poemas, cultivando o interesse dos alunos para os poetas ainda um pouco desconhecidos para o público chinês. Talvez num futuro não muito remoto, todos esses poetas possam ser trazidos para o público leitor chinês.

Tal como exposto, conforme o autor do manual, para esses poemas, os professores podem apenas fazer explicações bem simples para que os alunos tenham uma ideia básica e tentem memorizá-los. Na nossa perspectiva, com a declamação e memorização de poemas da língua portuguesa por parte dos alunos, o valor do ensino da literatura (poemas nesse caso) como motivação para a leitura, e como exemplar (sendo bem lidos em voz alta pelo docente para que os alunos sigam) da sonoridade da língua pode ser mais bem destacado. Exercícios assim, além da exercitação da oralidade dos alunos em relação ao português, também podem lançar um alicerce para o ensino da literatura no $3^{\circ}$ e $4^{\circ}$ ano da licenciatura (a licenciatura dura, geralmente, 4 anos na China).

Segundo a apresentação da Licenciatura da Língua Portuguesa pelas universidades chinesas (HONG, 2016, p. 116), o ensino da licenciatura de português enfatiza a formação das duas competências por parte dos alunos: a competência linguística (compreensão oral; oralidade; escrita; leitura; tradução) e a competência cultural (literatura e cultura portuguesa; literatura e cultura brasileira; cultura chinesa; português comercial; leitura dos jornais e publicações periódicas, entre outros).

O que Hong (2016, p. 116) indica acima pode ser considerado como uma apresentação geral do ensino da licenciatura de português pelas instituições chinesas. Para cada universidade, as disciplinas organizadas ainda podem variar um pouco. Por exemplo, na Universidade de Estudos Internacionais de Xi'an, oferece-se apenas a disciplina “Literatura dos

DOI: https://doi.org/10.32988/rep.v10n1.1156

Dossiê "Possibilidades de trabalho com a Língua Portuguesa"

\begin{tabular}{|l|l|l|l|l|l|l} 
Revista (Entre Parênteses) & Alfenas, MG & v. 10 & n. 1 & $1-24$ & e021010 & 2021 \\
\hline
\end{tabular}




\section{(")}

ISSN 2238-4502

Países Lusófonos (Portuguesa e Brasileira)" durante um semestre com 32 horas escolares ${ }^{9}$ e na Universidade de Estudos Internacionais de Xangai, oferecem-se não só a disciplina de "Literatura Portuguesa", mas também a de "Literatura Brasileira", cada uma tem uma duração de um semestre com 32 horas escolares.

Tanto uma disciplina que integra toda a literatura da língua portuguesa (32 horas escolares) quanto duas disciplinas separadas (a literatura portuguesa e a brasileira) (64 horas escolares), se for comparado com a literatura tão enriquecida da língua portuguesa (literatura portuguesa, literatura brasileira, literatura dos países africanos de língua portuguesa, literatura de Macau), ainda são bem escassas. Tendo tudo isso em conta, convém "antecipar" a formação literária no estudo dos licenciandos chineses de língua portuguesa.

Pela palavra "antecipar", não significamos antecipar as disciplinas literárias para o $1^{\circ}$ ou o $2^{\circ}$ ano escolar da licenciatura (as disciplinas de literatura geralmente são organizadas para o $3^{\circ}$ ou $4^{\circ}$ ano da licenciatura pelas instituições chinesas), o que queremos dizer é antecipar o trabalho docente para a consciência dos alunos em relação à formação literária, por exemplo, deixar que os alunos memorizem os poemas dos escritores conceituados da literatura de língua portuguesa (como o que exige o autor do manual).

No entanto, "memorizar" só, para nós, ainda não é suficiente. A nosso ver, convém que os alunos, além de decorar, também comecem realmente a tentar conhecer mais sobre os escritores lusófonos de mais renome mundial, quais as suas obras mais representativas, a que escola literária é que estes escritores pertencem. Além disso, nas aulas de língua deve permitirse aos alunos fruírem da sonoridade da língua - com boas leituras e excertos literários ou poemas, feitas pelos docentes ou reproduzidas de gravações feitas por atores profissionais; existem, online, muitos poemas lidos por bons atores.

Com tudo isso, antes de começarem as disciplinas literárias no $3^{\circ}$ ou $4^{\circ}$ ano, os alunos têm já uma base de motivação e gosto pela leitura da literatura em língua portuguesa, facilitando-se assim a sua entrada no mundo da literatura lusófona. Acresce-se que, se for possível, quando das explicações desses poemas, os professores podem informar os alunos da preparação básica para compreender e interpretar os poemas.

\subsection{Na série "Curso de Português para Chineses"}

Fruto da experiência de ensino de português pela Universidade de Estudos Internacionais de Xangai durante muitos anos (desde 1978), a série "Curso de Português para Chineses", de 4 volumes, tem como alvo principal os licenciandos chineses de português. Quanto ao padrão linguístico aplicado no ensino, no prefácio (XU \& ZHANG, 2012, p. i) do volume 1 da série, indica-se, logo de partida, que, dada a diferença fonética, lexical e gramatical entre o português continental e o português brasileiro, se adota, na série, o padrão linguístico

${ }^{9}$ Cada hora escolar corresponde a 45 minutos.

DOI: https://doi.org/10.32988/rep.v10n1.1156

Dossiê "Possibilidades de trabalho com a Língua Portuguesa"

\begin{tabular}{|l|l|l|l|l|l|l|} 
Revista (Entre Parênteses) & Alfenas, MG & v. 10 & n. 1 & $1-24$ & e021010 & 2021 \\
\hline
\end{tabular}




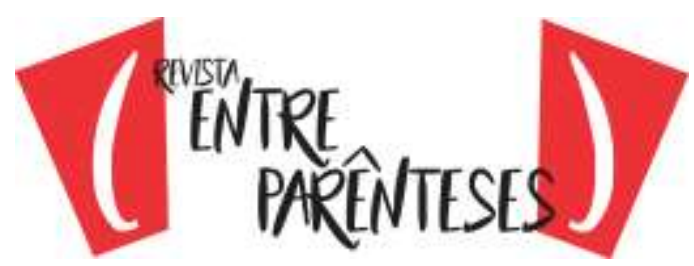

ISSN 2238-4502

do português europeu. Seguindo esse raciocínio, nos primeiros três manuais, quase todos os textos são escritos em português continental. Esta situação começa a ser mudada a partir da publicação do volume 4 (2016). Os quatro volumes não foram publicados simultaneamente, em vez disso, saíram sucessivamente em 2012, 2012, 2014 e 2016. No 4ov volume da série, cada unidade tem 2 textos: um adota o padrão do português europeu e o outro o do português brasileiro; no final de cada unidade, está incluído um texto como leitura adicional para os alunos.

Em relação aos temas envolvidos no volume, de acordo com os autores Zhang \& Xu (2016, p. i), a temática abordada no $4^{\text {o }}$ volume é mais variada, abarcando os tópicos da cultura e tradição, os costumes e hábitos, a sociedade, o meio ambiente, a economia de internet de Portugal e do Brasil. De acordo com a nossa análise, na realidade, os temas são bem mais variáveis do que indicam os autores no prefácio, por exemplo, o tópico de literatura também é abordado no volume, a unidade 10 destina-se exclusivamente a excertos de obras de escritores lusófonos.

\subsubsection{0 tópico da literatura no 4ํㅡㅁ volume da série "Curso de Português para Chineses"}

Tal como referido acima, o 4o volume da série tem 12 unidades e cada unidade tem 3 textos escolhidos pelos autores (os textos podem ser completos ou excertos). Com base na nossa pesquisa, no $4^{\circ}$ volume, toda a unidade 10 dedica-se ao tópico de literatura, que inclui 2 textos para a leitura nas aulas e 1 texto para leitura adicional. Nessa unidade, selecionam-se três excertos das obras dos escritores lusófonos.

Vejamos a seguinte tabela:

\begin{tabular}{|l|l|l|}
\hline Título do texto & Autor (nacionalidade) & Título da obra original \\
\hline $\begin{array}{l}\text { Arroz e Lágrima } \\
\text { (leitura nas aulas) }\end{array}$ & $\begin{array}{l}\text { Deolinda da Conceição (1913-1957) } \\
\text { (Macau, quando Macau estava sob } \\
\text { administração portuguesa) (Portugal) }\end{array}$ & A Cabaia \\
\hline $\begin{array}{l}\text { A Lição de Violão } \\
\text { (leitura nas aulas) }\end{array}$ & Lima Barreto (1881-1922) (Brasil) & $\begin{array}{l}\text { Triste Fim de Policarpo } \\
\text { Quaresma }\end{array}$ \\
\hline $\begin{array}{l}\text { Na Berma de Nenhuma Estrada } \\
\text { (leitura adicional) }\end{array}$ & Mia Couto (1955-) (Moçambique) & Na Berma de Nenhuma Estrada \\
\hline
\end{tabular}

Tabela 2: A organização dos textos na unidade 10 do 4ovolume da série "Curso de Português para Chineses"

Pelo observado na tabela, a seleção dos escritores reflete consideração em relação aos padrões linguísticos com que os autores têm se preocupado no volume: as três obras são escritas respetivamente em português continental, português brasileiro e português africano.

DOI: https://doi.org/10.32988/rep.v10n1.1156

Dossiê "Possibilidades de trabalho com a Língua Portuguesa"

\begin{tabular}{|l|l|l|l|l|l|l|}
\hline Revista (Entre Parênteses) & Alfenas, MG & v. 10 & n. 1 & $1-24$ & e021010 & 2021 \\
\hline
\end{tabular}




\section{("NinRE}

ISSN 2238-4502

Em relação aos escritores escolhidos, Deolinda da Conceição já tem uma obra traduzida em chinês: "A Cabaia" (traduzida por Yao Jingming, e publicada em 1996); Lima Barreto ainda é um nome pouco conhecido pelo público chinês, uma vez que nenhuma das suas obras foi traduzida para a língua chinesa. Relativamente aos outros dois escritores, nos últimos anos, Mia Couto tem sido um nome frequente para o público leitor chinês, tendo em conta que já várias das suas obras foram trazidas para o público leitor chinês em 2018 e 2019: "Jesusalm" (2018); "A Confissão da Leoa" (2018); "Terra Sonâmbula" (2018); "O Gato e o Escuro" (2019); “A Água e a Águia” (2019); “O Beijo da Palavrinha” (2019).

Com a popularização de Mia Couto no círculo literário nos últimos anos ${ }^{10}$ e a temática das suas obras focada principalmente na reflexão da história e realidades moçambicanas (pouco conhecida do público chinês), considerando que a literatura dos países africanos lusófonos é um nicho de mercado pouco explorado no continente chinês, a editora chinesa CITIC Press Corporation decidiu publicar uma série de obras de Mia Couto em colaboração com os professores jovens nas universidades chinesas. Porém, a obra "Na Berma de Nenhuma Estrada", de que se retira o excerto selecionado na Unidade 10 do manual, ainda não foi traduzida para o chinês. Talvez a escolha desse excerto seja uma chamada para mais atenção dos tradutores chineses para a tradução das obras de Mia Couto e de mais obras dos países africanos da língua portuguesa.

Quanto ao motivo da seleção da obra de Deolinda da Conceição, a nosso ver, isso tem relação com a temática abordada na obra: apesar do uso da língua portuguesa, como uma escritora nascida e vivida em Macau sob a administração portuguesa, todas as personagens da obra são chinesas e os juízos de valor transmitidos também têm a sua raiz na cultura chinesa. Além disso, a técnica de escrita que alia o fictício e o real inspira-se também na tradição cultural folclórica chinesa (Apresentação crítica na obra, 1996, p. 3). Com tudo isso, os contos integrados na obra de Deolinda da Conceição também podem ser considerados como contos chineses (Apresentação crítica na obra, 1996, p. 3). Parece-nos que tudo isso talvez constitua um motivo pelo qual um conto da dita obra tenha sido selecionado para o manual, para o estudo pelos alunos chineses de português, já que o conto, apesar de escrito em português, descreve, pormenorizadamente, a condição miserável e humilde de uma mãe chinesa em tempos de guerra, e a sua dor em não conseguir dar de comer ao seu filho. Por meio do estudo, os alunos podem tomar conhecimento da situação social da época de guerra de Macau, e o destino incontrolável, miserável e humilde das mulheres chinesas daquela altura em Macau.

Conforme exposto acima, nenhuma das obras de Lima Barreto foi introduzida ao público chinês. Isso se deve a vários fatores, tais como: o escritor não é contemporâneo, a maior parte das suas obras foram publicadas postumamente, e ele não ganhou nenhum prémio internacional, entre outros. Embora um excerto da sua obra "Triste Fim de Policarpo Quaresma" tenha sido escolhido para o manual, esse se encontra no início do capítulo I "A Lição

10 Em 2013, Mia Couto ganhou o Prémio Camões, um galardão do nível mais alto no círculo literário dos países lusófonos; em 2014, ele venceu o Neustadt International Prize for Literature, um dos prémios internacionais mais importantes nos Estados Unidos.

DOI: https://doi.org/10.32988/rep.v10n1.1156

Dossiê "Possibilidades de trabalho com a Língua Portuguesa"

\begin{tabular}{|l|l|l|l|l|l|l|} 
Revista (Entre Parênteses) & Alfenas, MG & v. 10 & n. 1 & $1-24$ & e021010 & 2021 \\
\hline
\end{tabular}




\section{(")}

ISSN 2238-4502

de Violão". Talvez pelo facto de o capítulo I da obra ter uma extensão grande, para facilitar o estudo pelos alunos chineses de português, foi escolhido só o início desse capítulo: Policarpo era um senhor respeitado pela vizinhança, que é aficionado pelos livros; um dia, ele foi descoberto a aprender a tocar violão, e as pessoas na vizinhança não conseguiam compreender o porquê de "um homem tão sério metido nessas malandragens" (ZHANG \& XU, 2016, p. 173). Na realidade, embora seja curto o excerto, pode considerar-se que, como uma história que tem um final de suspense, os alunos vão ficar curiosos em saber o motivo pelo qual "um senhor tão sério aprende a tocar violão"; ou seja, um excerto assim pode despertar o interesse dos alunosleitores, encorajando-os a ler por si próprios o resto da obra.

2.2.2 0 ensino dos textos literários no volume 4 da série "Curso de Português para Chineses"

Na parte 2.2.1., abordamos os escritores e as suas obras selecionadas no volume 4 da série "Curso de Português para Chineses": na unidade 10 do volume 4 dessa série, foram selecionados excertos das obras de três escritores lusófonos, que são: Deolinda da Conceição (Macau, na era da administração portuguesa), Lima Barreto (Brasil) e Mia Couto (Moçambique) (as três obras representam três padrões linguísticos: português continental, português brasileiro, português africano).

Nesta parte, iremos abordar, primeiro, as indicações de como se trabalham os textos literários da unidade 10 no $4^{\mathrm{o}}$ volume de acordo com os autores, depois proporemos as sugestões comparando o ensino dos textos literários na série "Curso de Português para Chineses" com o na série "Español Moderno". Essa é uma série de manuais de aprendizagem de espanhol que tem sido muito bem acolhida e usada em todas as instituições chinesas onde estão abertas as licenciaturas de Espanhol. A razão pela qual a escolhemos, como termo de comparação, consiste não só pela sua popularização durante muitos anos como material didático obrigatório para todas as licenciaturas de Espanhol no continente chinês (agora já existem três edições, com uma extensão de mais de 35 anos), mas também pela escolha e organização dos textos literários nessa série de manuais: os temas relacionados com a literatura são bem variados, pode-se encontrar tanto excertos das obras dos escritores hispanófonos, quanto textos que abordam certos fenómenos ou escolas literárias.

Quanto ao ensino dos textos literários no volume 4 da série "Curso de Português para Chineses", além da apresentação das obras e os seus escritores (abordada acima), também é preciso, a nosso ver, analisar o modo de ensinar tais conteúdos recomendado pelos autores. Depois da análise do manual, descobrimos que, no volume 4 (último volume da série), o foco continua sendo colocado na aprendizagem de itens novos de gramática ou na revisão de conteúdos gramaticais já aprendidos. Concretamente, em cada unidade, são feitas explicações dos verbos ou estruturas (que os autores acreditam serem importantes ou difíceis de compreender por parte dos alunos), e novas regras gramaticais.

DOI: https://doi.org/10.32988/rep.v10n1.1156

Dossiê "Possibilidades de trabalho com a Língua Portuguesa"

\begin{tabular}{|l|l|l|l|l|l|l} 
Revista (Entre Parênteses) & Alfenas, MG & v. 10 & n. 1 & $1-24$ & e021010 & 2021 \\
\hline
\end{tabular}




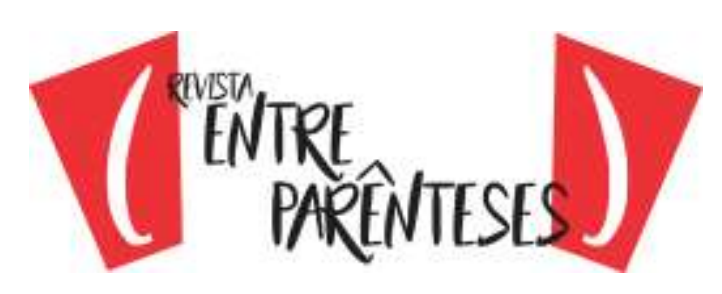

ISSN 2238-4502

Nos exercícios anexados no final de cada unidade, o enfoque também fica centrado na gramática. Quanto aos textos escolhidos em cada unidade, não se adiciona nenhum exercício correspondente, o que vemos são somente frases como "Leia o Texto 1 e o Texto 2" e "Leia o seguinte texto". Basicamente, pode-se afirmar que a vertente gramatical é sempre preferida na série, considerando que esse volume já é o volume 4, ou seja, o último volume da série.

Apesar do seu mérito em exercitar a competência linguística dos alunos chineses de português, no que concerne à exercitação da motivação literária dos alunos, o que observamos no manual ainda é insuficiente.

0 ensino dos textos literários na série "Español Moderno", conforme exposto anteriormente, aparece, pela primeira vez, no volume $3^{\circ}$, no qual, nas unidades 6,15 e 17, são escolhidos textos para a apresentação dos escritores mais conceituados no mundo hispanófono. Na unidade 6, Gabriel Garcia Márquez (ganhador do Prémio Nobel da Literatura em 1982) e o enredo da sua obra "Crónica de uma Morte Anunciada" são disponibilizados aos alunos; na unidade 15, o autor realiza uma breve apresentação do Boom Literário e o Realismo Mágico da Hispano-América; e na unidade 17, Miguel de Cervantes e uma introdução brevíssima da sua obra "Dom Quixote de la Mancha" são apresentados.

Em comparação com os excertos das obras selecionadas no manual de português mencionados em 2.2.1, a diferença é bem evidente: os três textos em espanhol, em vez de serem excertos, são textos escritos pelos próprios autores (Dong Yansheng e Liu Jian, professores na Faculdade de Espanhol e Português da Universidade de Estudos Estrangeiros de Beijing11), que combinam muito bem a apresentação dos escritores e a da resenha de uma das suas obras mais representativas (tais como Gabriel Garcia Márquez e a sua obra "Crónica de uma Morte Anunciada", e Miguel de Cervantes e a sua obra "Dom Quixote de la Mancha"), aliás, para cultivar o interesse dos alunos pela literatura da América Latina (Hispano-América), o autor ainda prepara um texto (unidade 15) para a apresentação do Boom Literário e o Realismo Mágico da Hispano-América. Voltando o nosso olhar para a parte de exercícios, descobrimos que, além do enfoque em exercitar a competência linguística dos alunos, há sempre partes dos exercícios dedicadas à compreensão textual e cultural dos alunos em relação aos textos literários. Por exemplo, na unidade 6 (sobre Gabriel Garcia Márquez e a sua obra "Crónica de uma Morte Anunciada"), há uma série de perguntas ligadas ao texto. Vejamos as seguintes perguntas retiradas dos exercícios dessa unidade por nós:

1. ¿Por qué se dice que Gabriel García Márquez es un escritor fecundo?

2. ¿A qué se debe el éxito y la fama del escritor?

3. ¿De qué novela es el resumen que leemos en el texto?

4. ¿Cómo era el pueblo en que se desarrolla el argumento?

11 Uma das melhores universidades chinesas de ensino de línguas estrangeiras.

DOI: https://doi.org/10.32988/rep.v10n1.1156

Dossiê "Possibilidades de trabalho com a Língua Portuguesa"

\begin{tabular}{|l|l|l|l|l|l|l} 
Revista (Entre Parênteses) & Alfenas, MG & v. 10 & n. 1 & $1-24$ & e021010 & 2021 \\
\hline
\end{tabular}




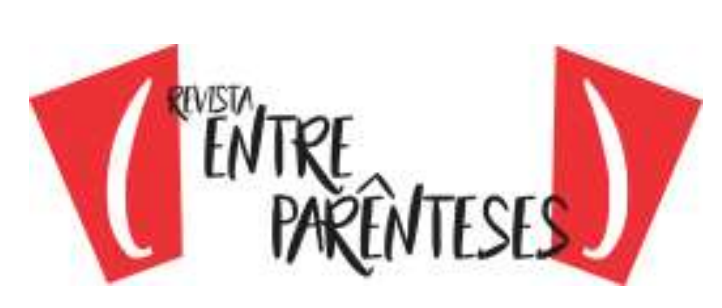

ISSN 2238-4502

5. ¿Por qué Bayardo San Román devolvió a Ángela Vicario a sus padres?

6. ¿Por qué los hermanos de Ángela se veían obligados a matar a Santiago?

7. ¿Crees que los dos gemelos realmente querían matar a Santiago en un principio?

8. ¿Por qué Santiago no estaba enterado del gran peligro que corría?

9. ¿Por qué Santiago no pudo entrar en casa para evitar que lo mataran?

10. ¿Qué nos quiere sugerir el autor con el trágico destino de Santiago Nasar? (DONG \& LIU, 2000, p. 171)

Pelo que se observa através dessas acima listadas, notamos que elas envolvem não só o conhecimento dos alunos para com o escritor, mas também a compreensão dos alunos do enredo da história narrada no texto. Além disso, essas questões também podem ser usadas pelos professores nas aulas para avaliar a compreensão dos alunos em relação ao texto, visto que são perguntas de compreensão textual, que permitem descortinar se os alunos compreendem a língua e podem levar a que leiam a obra completa.

A partir do volume 4ํ da série "Español Moderno", começam a surgir adaptações das obras dos escritores hispanófonos, por exemplo, a adaptação do conto "Final de Jornada" de Eulalia Galvarriato (unidade 5), a adaptação da "El Padre" de Olegario Lazo Baeza (unidade 9), a adaptação da "La Pulsera" de Mercedes Ballesteros (unidade 12). Considerando que a literatura, em muitos dos casos, apresenta fugas ao modelo de "correção" que o professor deseja dar aos alunos, torna-se necessário "adaptar" ou "simplificar" um texto literário, exercitando a compreensão textual (como fazem ao texto de Garcia Márquez - acima) dos alunos e motivando-os para a leitura posterior por si próprios.

Para facilitar a compreensão dos leitores em relação ao ensino dos textos literários nesse volume, iremos citar o exemplo da unidade 5, cujo texto escolhido é uma adaptação do "Final de Jornada" de Eulalia Galvarriato. Além de indicar logo no começo do texto que se trata de uma adaptação do conto do mesmo título por Eulalia Galvarriato, no final do texto está anexada uma parte dedicada à apresentação da autora. Vejamos as seguintes informações retiradas por nós:

Eulalia Galvarriato (1905 -): española

Novelas: Cinco sombras (1947), Raíces bajo el agua (1953)

Cuentos: Tres ventanas, los Hijos, Sólo un día cualquier, Final de jornada, etc.

Otros escritos: Dos niños de América (recuerdos de viaje), San Juan de la Cruz, comentarios en prosa a sus poemas mayores. (DONG, 2001, p. 153)

DOI: https://doi.org/10.32988/rep.v10n1.1156

Dossiê "Possibilidades de trabalho com a Língua Portuguesa"

\begin{tabular}{l|l|l|l|l|l|l} 
Revista (Entre Parênteses) & Alfenas, MG & v. 10 & n. 1 & $1-24$ & e021010 & 2021 \\
\hline
\end{tabular}




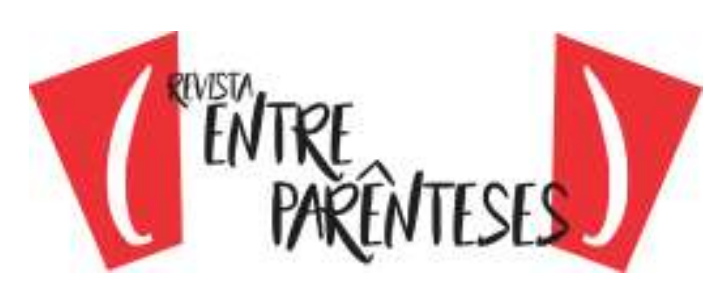

ISSN 2238-4502

I. En el texto se narran los cambios de relación que se iban produciendo entre padres e hijos. Notoriamente se detectan varias escenas bien delimitadas, según iban cambiando la situación. Divide el texto en diversas escenas y resume el contenido de cada una en una sola frase. Por ejemplo, los sacrificios que hacían los padres en favor de sus hijos y el cariño que reinaba en la familia; la gradual desunión de la familia a medida que crecían los hijos, etc. (DONG, 2001, p. 173)

Tais exercícios, além de facilitar a compreensão dos alunos do texto, ajudam também a exercitar a capacidade dos alunos a reescrever e sintetizar os conteúdos do texto.

Com base nas nossas análises dos textos literários integrados nos volumes da série "Español Moderno", podemos aferir que o ensino da língua por via dos textos literários é bem mais maduro nestes manuais de aprendizagem de espanhol; o que está refletido, basicamente, nos seguintes aspetos: (a). a escolha das obras dos escritores não só espanhóis, mas também latino-americanos; (b). os textos escolhidos são, geralmente, escritos pelos próprios autores (para o $3^{\circ}$ volume), adaptações ou excertos (para o 4ํㅜㄴ 5 e 6o volume da série); prática essa que serve para facilitar a compreensão dos alunos; (c). no final de cada texto adaptado ou excerto de obra, estão informações biográficas sobre os escritores e apresentações breves das suas obras representativas; (d). todos os textos estão acompanhados de exercícios diretamente ligados à compreensão dos mesmos textos.

Se comparamos o ensino dos textos literários na série "Español Moderno" com o na série "Curso de Português para Chineses", podemos notar as seguintes diferenças:

\begin{tabular}{|l|l|}
\hline $\begin{array}{l}\text { A Série “Curso de Português para } \\
\text { Chineses" }\end{array}$ & A Série “Espanhol Moderno" \\
\hline $\begin{array}{l}\text { Os textos literários escolhidos são excertos } \\
\text { das obras dos escritores lusófonos }\end{array}$ & $\begin{array}{l}\text { Os textos literários escolhidos têm três tipos: } \\
1 . \quad \text { Os escritos pelos autores (para o volume 3) } \\
\text { 2. As adaptações das obras dos escritores } \\
\text { hispanófonos (para o volume 4, 5 e 6) } \\
\text { Os excertos das obras dos escritores } \\
\text { hispanófonos (para o volume 4, 5 e 6) }\end{array}$ \\
\hline $\begin{array}{l}\text { Não existem informações biográficas dos } \\
\text { escritores nem apresentaçôes das obras } \\
\text { representativas destes escritores }\end{array}$ & $\begin{array}{l}\text { Existem tanto informações biográficas dos } \\
\text { escritores quanto apresentações das obras } \\
\text { representativas destes escritores }\end{array}$ \\
\hline $\begin{array}{l}\text { Não estão acompanhados de exercícios } \\
\text { diretamente ligados à compreensão dos } \\
\text { textos }\end{array}$ & $\begin{array}{l}\text { Estão acompanhados de exercícios diretamente } \\
\text { ligados à compreensão dos textos (os exercícios são } \\
\text { variados) }\end{array}$ \\
\hline
\end{tabular}

Tabela 3: A comparação do ensino dos textos literários nas séries "Curso de Português para Chineses" e "Español Moderno"

DOI: https://doi.org/10.32988/rep.v10n1.1156

Dossiê "Possibilidades de trabalho com a Língua Portuguesa"

\begin{tabular}{|l|c|c|c|c|c|c|}
\hline Revista (Entre Parênteses) & Alfenas, MG & v. 10 & n. 1 & $1-24$ & e021010 & 2021 \\
\hline
\end{tabular}




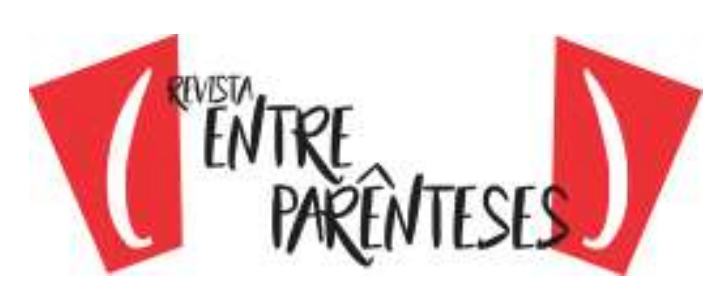

ISSN 2238-4502

Com base em tudo o que se expõe, podemos dar as seguintes sugestões para a melhoria do ensino dos textos literários nos manuais chineses de português:

1. Para os excertos das obras, pode-se oferecer informações sobre os seus autores, indicando as suas principais obras para que os alunos possam escolher como leitura adicional, caso estejam interessados;

2. Pode considerar-se a hipótese de elaborar textos para a apresentação de certos escritores lusófonos mais representativos em Portugal, no Brasil, nos países africanos de língua portuguesa, e em Macau, entre outros.

3. Convém que os textos estejam acompanhados, em cada unidade, de exercícios diretamente ligados à compreensão dos textos, ajudando assim os alunos a compreender melhor os conteúdos e o tema abordado neles.

\section{Notas conclusivas}

Neste trabalho, analisamos a relação entre a língua e a literatura em duas séries de manuais didáticos de português na China, com foco no ensino dos textos literários, nesses manuais. As análises levam-nos às seguintes considerações.

No que diz respeito aos dois volumes da série "Português para Ensino Universitário", não há muitos textos dedicados ao tema de literatura, o que encontramos são os trava-línguas incluídos nos exercícios de oralidade do volume 1, que, a nosso ver, podem ser considerados como sendo textos literários elementares, uma vez que integram em si elementos culturais do povo lusófono, e os poemas anexados no final das unidades do volume 2 (dos escritores tanto portugueses quanto brasileiros, sendo os poetas portugueses a ocupar uma percentagem alta). Tal como indicado na nossa análise, conforme o autor no prefácio (não paginado), os professores precisam apenas de oferecer explicações simples, e o mais importante, do ponto de vista do autor, é exigir dos alunos que guardem os poemas na memória.

Talvez por causa disso, os poemas não estão acompanhados nem de informações biográficas dos autores nem exercícios destinados à compreensão dos alunos relativamente aos textos. Organização essa, em nosso entender, também se deve ao facto de que a série, por enquanto, tem só dois volumes, que são usados, geralmente, para a aprendizagem nos primeiros dois anos da licenciatura, visto que, nesta fase, o mais importante é elevar a competência linguística dos alunos. No prefácio da série "Português para Ensino Universitário" consta que serão publicados mais volumes da série, e esperamos que possam ser incluídos mais textos literários nos volumes vindouros.

No que se refere à série "Curso de português para Chineses" (que já tem todos os volumes publicados), a unidade 10 do volume 4 da série é destinada exclusivamente ao estudo dos textos literários: são incluídos, nesta unidade, três textos-excertos das obras dos escritores lusófonos: Deolinda da Conceição, Lima Barreto e Mia Couto. Organização essa reflete a consideração dos autores com o padrão linguístico do português como uma língua

DOI: https://doi.org/10.32988/rep.v10n1.1156

Dossiê "Possibilidades de trabalho com a Língua Portuguesa"

\begin{tabular}{|l|l|l|l|l|l|l|} 
Revista (Entre Parênteses) & Alfenas, MG & v. 10 & n. 1 & $1-24$ & e021010 & 2021 \\
\hline
\end{tabular}




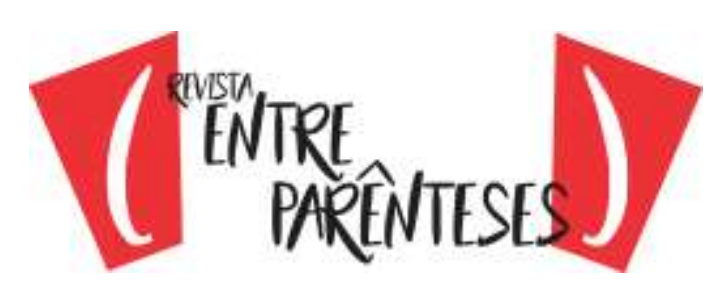

ISSN 2238-4502

internacional (português europeu, português brasileiro e português africano). Quanto ao ensino dos três textos literários, são indicadas frases como "Leia o Texto 1 e o Texto 2" e "Leia o seguinte texto" nos exercícios. Na realidade, não vemos uma diferença aqui, se levamos em conta o que é indicado em outras unidades cujos textos não são literários; ou seja, os autores adotam uma atitude uniformizada em relação a todos os textos (sejam literários sejam não literários).

Quanto a isso, temos as seguintes considerações.

1. No que diz respeito aos textos literários e os não literários, dada a sua índole diferente, devem-se adotar atitudes diferentes no ensino: para os literários, os professores podem dar explicações não somente sobre os conhecimentos linguísticos, mas também conhecimentos literários (elementares) de que os alunos, como licenciandos de língua portuguesa, precisam. Estes conhecimentos podem incluir as informações biográficas dos autores e as suas obras representativas, posições literárias que esses autores sustentam, escolas literárias a que os escritores pertencem, etc.

2. Além dos exercícios destinados ao domínio das regras gramaticais pela parte dos alunos, devem-se também preparar exercícios associados à compreensão dos textos literários, por exemplo, pode-se organizar uma série de perguntas ligadas aos textos para observar se os alunos realmente já compreendem os conteúdos dos textos.

3. Em comparação com a quantidade dos textos não literários, o número dos textos literários ainda é muito limitado. A nosso ver, o número ainda pode ser elevado. A língua portuguesa, como um idioma internacional, constitui a pluma de muitos escritores excelentes, que são oriundos de culturas tão diferentes e enriquecidas, mas, na realidade, em comparação com a literatura inglesa, a francesa e a americana, durante muitos anos, a literatura em língua portuguesa tem ocupado um lugar marginalizado no mercado chinês tanto na quantidade dos volumes publicados como na influência exercida sobre os leitores. Isso quer dizer que a literatura lusófona precisa da nossa acrescida atenção e que a inclusão de textos literários pode ser considerada como uma motivação para leituras futuras.

4. Os três textos escolhidos no volume 4 da série "Curso de português para Chineses" são todos excertos das obras dos escritores lusófonos. No nosso entendimento, essa prática pode ser ainda ampliada, ou seja, além dos excertos, os autores também podem incluir adaptações das obras lusófonas ou textos escritos por si próprios que abordam certos escritores e suas obras. Assim, pode-se acompanhar as dificuldades que surgem eventualmente no estudo pela parte dos alunos. Se certas obras são difíceis para a compreensão dos alunos, os autores podem adaptar para um acesso mais fácil dos alunos. Para certas obras de extensão bem longa, uma resenha talvez seja uma boa solução.

Quanto ao ensino dos textos literários nos manuais didáticos de português publicados no continente chinês, apesar do seu mérito inédito, há ainda certos aspetos que podem ser melhorados: os autores podem considerar a hipótese de se inspirar nos manuais didáticos disponíveis de outros idiomas estrangeiros já mais usados por professores e com mais

DOI: https://doi.org/10.32988/rep.v10n1.1156

Dossiê "Possibilidades de trabalho com a Língua Portuguesa"

\begin{tabular}{|c|c|c|c|c|c|c|} 
Revista (Entre Parênteses) & Alfenas, MG & v. 10 & n. 1 & $1-24$ & e021010 & 2021 \\
\hline
\end{tabular}




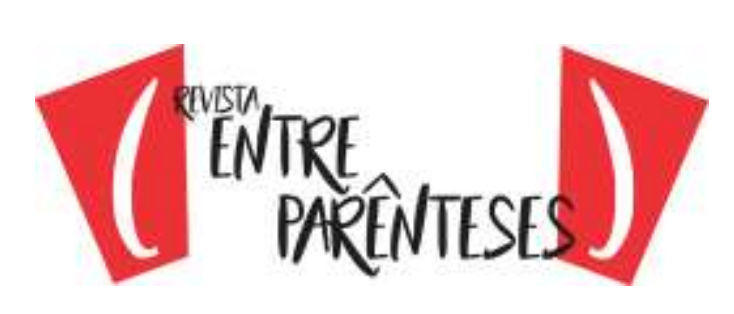

ISSN 2238-4502

tempo no mercado, tal como a série "Español Moderno" citado por nós na nossa análise. Esperamos sinceramente que o nosso trabalho possa contribuir um pouco para o ensino da língua portuguesa na China.

\section{Referências}

ANDRESEN, Sophia de Mello Breyner; Trad. Yao Jingming. Poemas de Sophia. Shijiazhuang, Editora Montanha das Flores, Instituto Cultural de Macau, 1995.

CAMÔES, Luís de; Trad. Xiao Jiaping. Coletânea dos Poemas de Luís de Camões. Beijing, Instituto de Literatura Estrangeira da Academia de Ciências Sociais da China, Fundação Calouste Gulbenkian, 1981.

CONCEIÇÂO, Deolinda de; Trad. Yao Jingming. Cabaia. Shijiazhuang, Editora Montanha das Flores, Instituto Cultural de Macau, 1996.

DONG, Yansheng; LIU, Jian. Español Moderno. Volume 3. Beijing, Foreign Language Teaching and Research Press, 2000.

DONG, Yansheng. Español Moderno. Volume 4. Beijing, Foreign Language Teaching and Research Press, 2001.

DONG, Yansheng. Español Moderno. Volume 5. Beijing, Foreign Language Teaching and Research Press, 2002.

DONG, Yansheng. Español Moderno. Volume 6. Beijing, Foreign Language Teaching and Research Press, 2007.

HONG, Ao; Detailed Introduction and Selection Guide of Major for College Entrance Examinations. Beijing, Beijing Institute of Technology Press, 2016.

JIANG, Jincheng; Gong, Xi. Foreign Love Short Poems. Shanghai, Shanghai Cultural Publishing House, 1986.

PESSOA, Fernando; Trad. Yang Zi. Selection of Poems of Fernando Pessoa. Shijiazhuang, Hebei Education Press, 2004.

PESSOA, Fernando; Trad. Jin Guoping. Mensagem. Macau, Instituto Cultural de Macau, 1986.

QIU, Yuan; WEI, Fan. Selected Love Poems. Beijing, China Federation of Literary and Art Circles Publishing House, 1986.

WANG, Suoying. A Língua Portuguesa na China. Acessível em http://varialing.web.ua.pt/wpcontent/uploads/2017/03/WANG PLE1.pdf, 2001.

WANG, Zhongxiang; LIU, Yuan. Selected Foreign Literature Works. Wuhai, Changjiang Literature Art Publishing House, 1996.

DOI: https://doi.org/10.32988/rep.v10n1.1156 Dossiê "Possibilidades de trabalho com a Língua Portuguesa"

\begin{tabular}{|l|c|c|c|c|c|c|} 
Revista (Entre Parênteses) & Alfenas, MG & v. 10 & n. 1 & $1-24$ & e021010 & 2021 \\
\hline
\end{tabular}




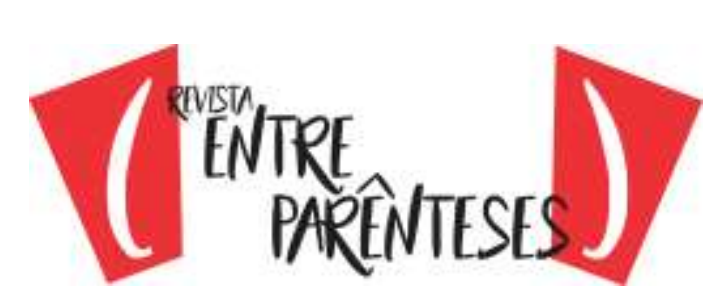

ISSN 2238-4502

XU, Yixing; ZHANG, Weiqi. Curso de Português para Chineses, Livro do Aluno 1. Shanghai, Shanghai Foreign Language Education Press, 2012.

XU, Yixing; ZHANG, Weiqi. Curso de Português para Chineses, Livro do Aluno 2. Shanghai, Shanghai Foreign Language Education Press, 2012.

XU, Yixing; ZHANG, Weiqi. Curso de Português para Chineses, Livro do Aluno 3. Shanghai, Shanghai Foreign Language Education Press, 2014.

ZHANG, Weiqi; XU, Yixing. Curso de Português para Chineses, Livro do Aluno 4. Shanghai, Shanghai Foreign Language Education Press, 2016.

YE, Zhiliang. Português para Ensino Universitário, Volume 1. Beijing, Foreign Language Teaching and Research Press, 2009.

YE, Zhiliang. Português para Ensino Universitário, Volume 2. Beijing, Foreign Language Teaching and Research Press, 2010.

Recebido em 09/06/2020

Aceito em 06/01/2021

Publicado em 30/06/2021

DOI: https://doi.org/10.32988/rep.v10n1.1156

Dossiê "Possibilidades de trabalho com a Língua Portuguesa" 


\title{
ON TEACHING LITERARY TEXTS IN PORTUGUESE TEXTBOOKS IN CHINA
}

\author{
Zhihua Hu \\ Zhejiang International Studies University \\ (China) \\ (zhihua.hu@ua.pt,_ramonhu@outlook.com)
}

\author{
Maria Teresa Roberto \\ Universidade de Aveiro (Portugal) \\ mariateresaroberto@ua.pt
}

\begin{abstract}
In this work, we intend to analyze the relationship between language and literature in two series of textbooks used to teach Portuguese in China, with a focus on the teaching of literary texts in these textbooks. Two series of textbooks to teach Portuguese were chosen: "Português para Ensino Universitário" and "Curso de Português para Chineses". In the analysis, we evinced that, in the first series, there are only tongue twisters and poems that can be considered literary texts; and in the second series, there is a unit dedicated exclusively to literary texts. However, in comparison with the more mature textbooks of other foreign languages (such as the series of textbooks "Español Moderno"), the teaching of literary texts in the two series of Portuguese textbooks still has several aspects in need of improvement, such as the insufficient number of literary texts, the lack of exercises that focus on the comprehension of literary texts as well as the biographical information of the authors, among others.
\end{abstract}

Keywords: Teaching of literature. Textbooks of Portuguese. Chinese institutions. Bachelor in Portuguese.

DOI: https://doi.org/10.32988/rep.v10n1.1156

Dossiê "Possibilidades de trabalho com a Língua Portuguesa"

\begin{tabular}{|l|l|l|r} 
Revista (Entre Parênteses) & Alfenas, MG & v. 10 & n. 1 \\
\hline
\end{tabular}

Departamento de Letras - Instituto de Ciências Humanas e Letras

Rua Gabriel Monteiro da Silva, 700 - Alfenas/MG - CEP 317131-001 - Brasil

https://publicacoes.unifal-mg.edu.br/revistas/index.php/entreparenteses/about 


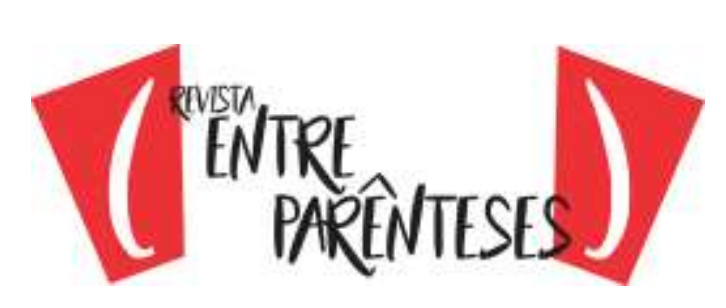

ISSN 2238-4502

\title{
SOBRE LA ENSEÑANZA DE LOS TEXTOS LITERARIOS EN LOS MANUALES DIDÁCTICOS DE PORTUGUÉS EN CHINA
}

\author{
Zhihua $\mathrm{Hu}$ \\ Zhejiang International Studies University \\ (China) \\ (zhihua.hu@ua.pt,_ramonhu@outlook.com)
}

\author{
Maria Teresa Roberto \\ Universidade de Aveiro (Portugal) \\ mariateresaroberto@ua.pt
}

\section{Resumen}

Resumen: En este trabajo, analizamos la relación entre lengua y literatura en dos series de manuales de portugués en China, con un enfoque en la enseñanza de textos literarios en estos manuales. Se eligieron dos series de manuales de portugués: "Português para Ensino Universitário" y "Curso de Português para Chineses". En el análisis se evidenció que, para la primera serie, existen sólo trabalenguas y poemas que pueden ser considerados como textos literarios; y para la segunda serie, hay una unidad destinada exclusivamente a textos literarios. Sin embargo, en comparación con los manuales más maduros de otras lenguas extranjeras (como la serie "Español Moderno"), la enseñanza de los textos literarios en las dos series de manuales de portugués tiene aún varios aspectos que mejorar, tales como la cantidad insuficiente de textos literarios, la falta de ejercicios destinados a la comprensión de los textos literarios y de las informaciones biográficas de los escritores, entre otros.

Palabras clave: Enseñanza de la literatura. Manuales de português. Instituciones Chinas. Licenciatura en português.

DOI: https://doi.org/10.32988/rep.v10n1.1156

Dossiê "Possibilidades de trabalho com a Língua Portuguesa"

\begin{tabular}{|l|l|l|l} 
Revista (Entre Parênteses) & Alfenas, MG & v. 10 & n. 1
\end{tabular}

